\title{
Does Helica treatment of early endometriosis confer short- and long-term benefits in terms of pain relief and sub-fertility?
}

\author{
Jill Adamson • Janani Iyer • Shamma Al-Inizi
}

Received: 30 January 2013 / Accepted: 11 June 2013 /Published online: 13 July 2013

(C) Springer-Verlag Berlin Heidelberg 2013

\begin{abstract}
Early-stage endometriosis is a known contributing factor for chronic pelvic pain and sub-fertility. To determine whether Helica Thermal Coagulation is an effective short- and long-term treatment for endometriosis-associated chronic pelvic pain and sub-fertility. Thirty six patients were followed up from 6 weeks to 1 year post-Helica treatment of early endometriosis. Pain relief was assessed subjectively. Eight of the women suffered from sub-fertility in addition to pelvic pain, while three patients suffered from sub-fertility alone. Ninety-three percent were pain free at 6 weeks, $75 \%$ were pain free at 6 months and $37.5 \%$ remained pain free at 1-year follow-up. Of those who continued to have pain at 1-year follow-up, three had repeated Helica treatment, two had hysterectomy and bilateral salpingoopherectomy, and the rest were commenced on different hormonal treatment to control endometriosis. Ten women (62\%) conceived within 1 year of treatment. Helica coagulation seems to be an effective way of treating early endometriosis-associated pelvic pain and sub-fertility. However, its effects only seem to be short term, with a decline in symptom relief and pregnancy rate over the 12-month postoperative period. Larger RCT are required.
\end{abstract}

Keywords Endometriosis $\cdot$ Helica Thermal Coagulation · Sub-fertility

\section{Introduction}

Endometriosis is one of the most common gynaecological conditions. It is defined as the presence of endometrial-like tissue outside the uterus, which induces a chronic, inflammatory reaction [1]. The most commonly affected areas are the

J. Adamson $(\bowtie) \cdot J$. Iyer $\cdot$ S. Al-Inizi

Department of Obstetrics and Gynaecology,

South Tyneside Hospital, South Shields, UK

e-mail: j.l.adamson@hotmail.co.uk pelvic organs and peritoneum. The exact pathophysiology of endometriosis remains uncertain. However, the most accepted theory is that of retrograde menstruation [2].

The condition is predominantly found in women of reproductive age, from all ethnic and social groups. Symptoms include severe dysmenorrhoea, deep dyspareunia, chronic pelvic pain, ovulation pain, infertility and dyschezia. Many are in fact asymptomatic, making the diagnosis of endometriosis rather difficult and can only be confirmed by visualisation, for example, at laparoscopy, which is the gold standard for diagnosing the disease [1].

The prevalence in the female population is difficult to measure as so many women go undiagnosed or misdiagnosed; however, it is estimated to be approximately $10 \%$ [3].

Nowadays, it is generally accepted that there is a strong link between endometriosis and infertility. Studies have shown endometriosis to have a prevalence of $0.5 \%-5 \%$ in fertile women compared with a much higher prevalence of $25 \%-40 \%$ in infertile women [4]. Although the exact nature of this link is not yet fully understood, it is suggested there is a multi-factorial element to it [5], for example, altered hormonal and cell-mediated function, ovulatory and peritoneal fluid abnormality, anatomical disorders, poor embryo quality and impairment of implantation [5-7].

Treatment of endometriosis can be either medical or surgical. While medical treatment such as 6 months of GnRH analogues provides most with symptom relief, long-term follow-up studies show a high recurrence rate $[8,9]$. Laparoscopic surgery has allowed us to use this minimally invasive technique not only to diagnose but also to treat endometriosis by excision or ablation of the lesions using laser, monopolar or bipolar diathermy. Despite these developments, the optimal therapy for endometriosis-associated pelvic pain has yet to be established [10].

The Helica Thermal Coagulator is a relatively new treatment method used for endometriosis. It is produced by a British company based in Edinburgh, which was founded by 
Mr Maurice M. Howieson in 1993. It uses a combination of low-level electrical power (2-8 W) combined with helium gas, which produces a beam that causes coagulation and haemostasis to endometrial tissue [11, 12]. While destroying the endometrial tissue, it also destroys the nerve endings, allowing immediate pain relief. It has been shown to be a safer, cheaper and more effective method of treatment of endometriosis compared with medical treatment [13].

\section{Aims and objectives}

While there are studies confirming the short-term benefits of the effectiveness of Helica Thermal Coagulator (TC) in the treatment of minimal to mild endometriosis-associated pain and infertility, there are no studies looking at the longer term benefits. The aim of our study was to look at the long-term effects of Helica TC on minimal to mild endometriosisassociated pain and infertility.

\section{Method}

This was a prospective observational study carried out between Oct 2009 and April 2012. A total of 36 patients were included in the study. Criteria for inclusion in the study were a confirmed diagnosis of stage 1 or 2 endometriosis at laparoscopy according to the American Fertility Classification [14] with one or more of the following symptoms: dysmenorrhoea, dyspareunia or subfertility. No treatment for endometriosis had been given at least 6 months prior to their Helica TC treatment.

Their ages ranged from 17 to 50 years, with a mean age of 32 years. Of the 36 patients, 25 patients complained of pain only, 8 complained of both pain and sub-fertility and 3 complained of sub-fertility alone.

Of those patients complaining of sub-fertility, three (27\%) suffered from primary sub-fertility and eight (73\%) suffered from secondary sub-fertility.

All patients were seen in clinic by a gynaecologist, and a full history and examination were performed. Informed consent was then taken, including an explanation of the risks of laparoscopy and Helica TC.

All procedures were performed as a day case. Laparoscopy was performed by the same surgeon, and staging of the endometriosis was done according to the American Fertility Society revised classification of endometriosis [14]. The lesions of endometriosis were seen mostly in Pouch of Douglas, vesicouterine pouch, ovaries and pelvic peritoneum. Most of the lesions were black and red endometriosis. There were no cases with pelvic adhesions and endometriomas included in the study as only early (grades I and II) cases were included. There was no correlation between the pain symptoms and location of lesions. There was no histological confirmation of endometriosis, and diagnosis was made by visualisation of endometriotic implants laparoscopically. The Helica TC was used to treat all visible spots of endometriosis. The probe is placed 3-4 $\mathrm{mm}$ from the target, and fulguration occurs after few seconds of treatment. Following the procedure, suction irrigation of the peritoneal cavity was done, and approximately $300 \mathrm{ml}$ of Hartmann's solution was instilled to prevent future intra-peritoneal adhesions. Patients were not prescribed with any medical treatment for endometriosis following the procedure.

Patients were followed up prospectively for pain relief and pregnancy in the gynaecology outpatient clinics at 6 weeks, 6 months and a year post-Helica TC treatment. On review, they were asked to rate their pain relief as no change, satisfactory relief or pain free. Confirmation of pregnancy was done by early sonographic identification of an intrauterine gestation sac with fetal pole and fetal heartbeat. Routine antenatal care was provided, and patients were followed up until delivery.

\section{Results}

Two patients were excluded as they were lost to follow-up immediately after their laparoscopic Helica TC treatment. A further three patients were excluded as another cause for their chronic pelvic pain was found during the year postHelica TC treatment, two were gastroenterology related, and one was orthopaedic related. Therefore, a total of 31 patients were included in the study results.

Figure 1 shows the percentage of pain relief according to the duration of post-Helica treatment.

Of the 31 patients who were followed up post-operatively, 20 patients complained of pain only, 8 complained of both pain and sub-fertility, and 3 complained of sub-fertility alone.

Of the 28 patients who complained of chronic pelvic pain, at their 6-week follow-up, 2 patients ( $7 \%$ ) had no change in their pelvic pain and $26(93 \%)$ were either satisfied or completely pain free. At their 6-month follow-up, four patients were excluded as they were pregnant and could not put the relief of their pain down to the Helica TC treatment alone. Therefore, of the 24 patients remaining, 18 (75\%) were satisfied or pain free. At their 1-year follow-up, a further five patients were excluded due to pregnancy, one was excluded as she was started on the combined contraceptive pill due to unmanageable pelvic pain, and a further two were excluded after starting on $\mathrm{GnRH}$ analogues following their 6-month appointment for the same reason. Of the 16 patients remaining, only $37.5 \%$ were pain free or satisfied with their pain relief.

Figure 2 shows the time period post-operatively at which the pain of patients who had initially seen an improvement in their symptoms recurred.

Of those patients who had recurrence of their pain at their 1year follow-up, two had a hysterectomy and bilateral salpingo- 


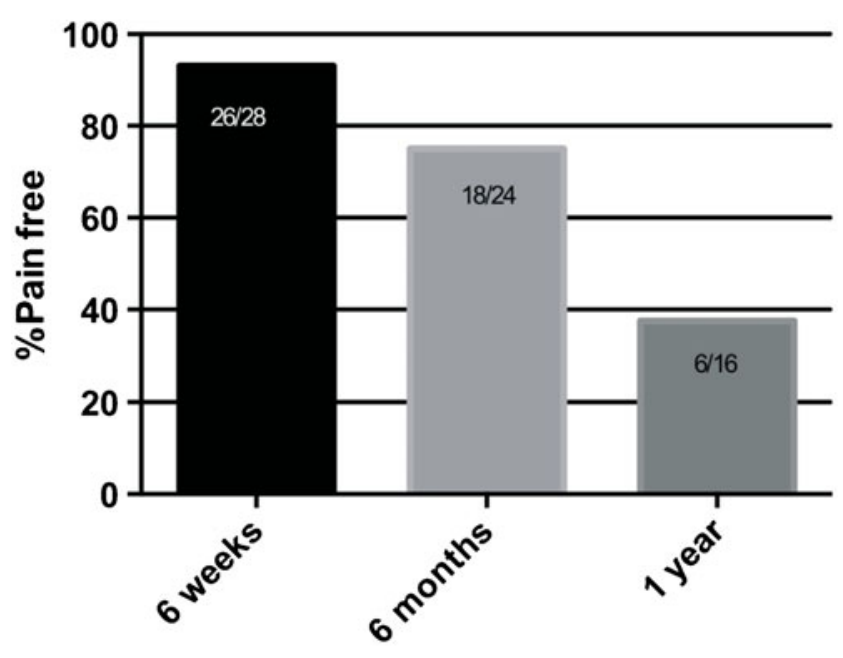

Fig. 1 Graph to show the percentage of patients with pain free or satisfactory pain relief following Helica TC

oophorectomy, three had repeated Helica TC treatment, one had Zoladex, and one started on the combined contraceptive pill.

Of the 11 sub-fertility patients, five became pregnant within a year following Helica TC treatment, giving a cumulative pregnancy rate of $45 \%$ over the year.

During the 1-year follow-up of these patients post-Helica $\mathrm{TC}$, there were a further five pregnancies in patients who had not complained of sub-fertility initially. This gives a total of ten pregnancies in women up to a year postHelica TC treatment, giving a $62 \%$ cumulative pregnancy rate over the year. Seven patients became pregnant with no ovulation induction medication, and three patients conceived while taking ovulation induction medication. Eight pregnancies were ongoing and went to

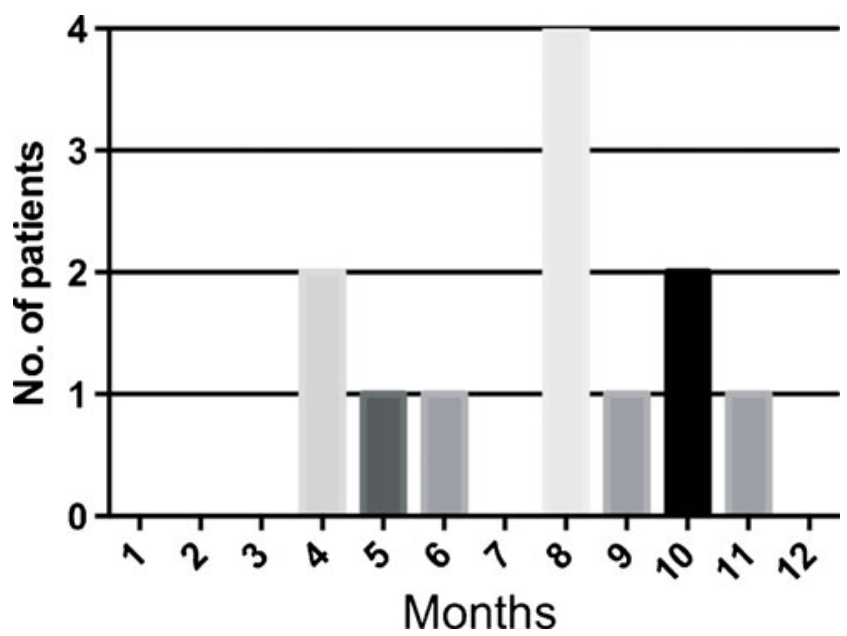

Fig. 2 Graph to show time period at which the patients' pain recurred post-operatively term; unfortunately, two of the pregnancies ended in early miscarriage.

Figure 3 shows that there is a steady pregnancy rate over the 1 year post-Helica TC treatment.

\section{Discussion}

The treatment of choice for minimal/mild endometriosisassociated chronic pelvic pain and infertility remains a widely debated topic. Endometriosis is a recurrent disease, which makes the treatment of it rather challenging, and the majority of women are not going to improve if left untreated $[15,16]$.

Medical treatment for endometriosis-associated pelvic pain is associated with a high recurrence rate as well as side effects, compared to surgical excision or ablation $[15,17-19]$. However, the optimal method for surgical destruction of endometriotic implants remains the subject of ongoing debate [20, 21].

Our study has shown Helica TC to be an effective treatment of minimal to mild endometriosis-associated pelvic pain with a $93 \%$ improvement in pain relief 6 weeks postoperatively. However, it seems that the benefits are only short term with only $75 \%$ improvement rate 6 months post-operatively and $37.5 \%$ improvement 1 year postoperatively. Other studies have found a good improvement rate in pain relief up to 6 months post-operatively, but no other studies have looked at the longer term effect of Helica TC. Al-Inizi et al. reported $72 \%$ improvement in pain 6months post-operatively [7]. Nardo et al. found a $74.4 \%$ improvement in pain relief 3 months post-operatively and $87.4 \%$ improvement 6 months post-operatively [12].

The possible reason behind the high recurrence rate of pain related to endometriosis post-Helica treatment could be

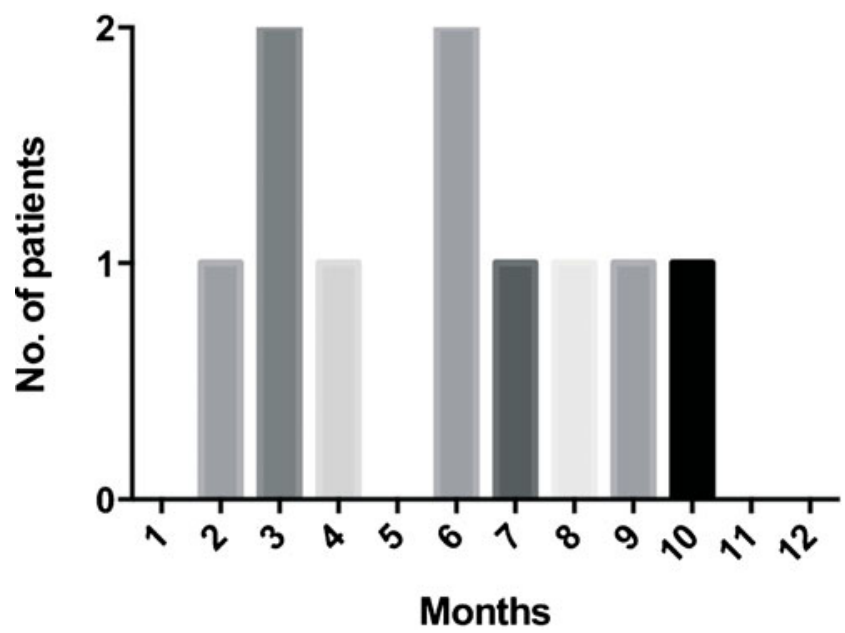

Fig. 3 Graph to show the number of pregnancies up to 12 months postHelica TC 
related to the superficial effect of this procedure on the endometriotic implants resulting in the incomplete treatment of the implants and recurrence of symptoms.

The management of endometriosis-associated infertility is difficult. Treatment choices include conservative management, medical treatment such as GNRH analogues, OCP and Danazol, and conservative surgical therapy as well as assisted reproductive technologies. Hull et al. reported a $55 \%$ cumulative pregnancy rate at 30 months after expectant management [22]. A comprehensive review in 2007 examining 24 randomised controlled trials concluded that pregnancy outcomes did not improve from treatment with ovulation suppression agents compared to placebo [23]. The drugs merely delay fertility. In accordance with the review findings, the ESHRE guideline 2005 [24] for the diagnosis and treatment of endometriosis does not recommend the suppression of ovarian function alone to improve fertility. It also indicates that ablation of endometriotic lesions plus adhesiolysis to improve fertility in minimal to mild endometriosis is beneficial compared to diagnostic laparoscopy alone $[24,25]$. A large Canadian randomised controlled trial found a cumulative pregnancy rate of $30.7 \%$ up to 36 weeks post-operatively following laparoscopic surgical treatment, compared with $17.7 \%$ in the control group who had just a diagnostic laparoscopy [26].

While it is well reported that laparoscopic surgical management of endometriosis-associated infertility is superior to medical treatment [26], the optimum method of laparoscopic treatment however remains an ongoing source of controversy with technology advancing as new devices are developed.

A number of studies have shown the effectiveness of Helica $\mathrm{TC}$ in treating minimal to mild endometriosis-associated infertility. Nardo et al. found a $23.2 \%$ cumulative pregnancy rate over a year post-Helica TC treatment [11]. After this, Al-inizi et al. found a $34 \%$ cumulative pregnancy rate up to 6 months post-operatively [7]. Our study gives an even higher cumulative pregnancy rate of $62 \%$ a year post-operatively.

Helica TC has been shown to be a safe, cost-effective and successful way of treating endometriosis-associated pelvic pain laparoscopically $[13,27]$. Unlike laser therapy or electrosurgery, the Helica TC minimises tissue ischaemia, charring and desiccation, which are potential causes of adhesions and persistent pelvic pain and infertility [11, 12, 28]. Helica TC may have a more rapid healing rate due to its limited depth of penetration and ability to precisely dissect adhesions as well as their reduced recurrence rate. Pelvic adhesions can impair oocyte release from the ovary and inhibit ovum pick up or transport [29]. The Helica TC can be performed at the time of diagnosis at laparoscopy, and as shown in our study, the pregnancy rate is highest in 2-6 months post-treatment.

Helica TC will treat the active visible endometriotic lesions. However, non-pigmented lesions or deep lesions will be missed. This may account for the failure rate of $7 \%$ in terms of pelvic pain relief initially at 6-week follow-up in our study [30-32].

\section{Conclusion}

Helica TC seems to be a safe, cheap and effective short-term surgical treatment for women suffering with minimal to mild endometriosis-associated pelvic pain and infertility. However, its effects seem to decline after 12 months post-operatively. It therefore appears that Helica TC is an effective short-term treatment for chronic pelvic pain associated with minimal to mild endometriosis, and patients need to be aware of this possible short-term benefit. The recurrence of symptoms can be due to the superficial effect of Helica on the endometriotic implants resulting in possible incomplete treatment.

With a cumulative pregnancy rate of $45 \%$ up to 1 year post-Helica TC, this study would suggest that performing a diagnostic laparoscopy and Helica TC is by far an optimal treatment choice for sub-fertility, compared with medical treatment where chances of conceiving are delayed whilst ovulation is suppressed.

The benefits of Helica TC compared with other conservative laparoscopic approaches such as laser and electrocoagulation, medical and expectant management have not been looked at in this study. Larger randomised controlled trials need to be carried out to confirm the advantages of Helica TC found in this study and others, and to compare Helica TC with other tools such as bipolar cautery and laser treatment.

\section{References}

1. The Royal College of Obstetricians and Gynaecologists. The investigation and management of endometriosis. Green top guideline No. 24. (RCOG, London, 2006).

2. Sampson J (1927) Peritoneal endometriosis due to menstrual dissemination of endometrial tissue into the peritoneal cavity. Am J Obstet Gynaecol 14:422-469

3. Eskenazi B, Warner ML (1997) Epidemiology of endometriosis. Obstet Gynaecol Clin N Am 24:235-258

4. Houston DE et al (1987) Incidence of pelvic endometriosis in Rochester, Minnesota 1970-1979. Am J Epidemiol 125:959-969

5. Ziegler D, Borghese B, Chapron C (2010) Endometriosis and infertility: pathophysiology and management. Lancet 376:730-738

6. Collinet P, Decanter C, Lefebvre C, Leroy JL, Vinatier D (2006) Endometriosis and infertility. Gynaecol Obstet Fertil 34:379-384

7. Al-Inizi S, Bamigboye V (2007) Laparoscopic Helica Thermal Coagulation for the treatment of early endometriosis. J Gynaecol Surg 2:45-52

8. Minjarez DA, Chaff WD (2000) Update on the medical treatment of endometriosis. Obstet Gynaecol Clin N Am 7(3):641-651

9. Wellberry C (1999) Diagnosis and treatment of endometriosis. Am Fam Physician 60(6):1753-1762

10. Valle R, Sciarra J (2003) Endometriosis: treatment strategies. Ann N Y Acad Sci 997:229-239 
11. Nardo L, Moustafa M, Beynon G (2006) Reproductive outcome after treatment of minimal or mild endometriosis using Helica Thermal Coagulator. Eur J Obstet Gynaecol Reprod Biol 126:264-267

12. Nardo L, Moustafa M, Beynon G (2005) Laparoscopic treatment of pelvic pain associated with minimal and mild endometriosis with use of the Helica Thermal Coagulator. Fertil Steril 83(3): $735-738$

13. Lalchandani S, Baxter A, Phillips S (2005) Is helium thermal coagulator therapy for the treatment of women with minimal to moderate endometriosis cost-effective? Gynaecol Surg 2:255-258

14. The American Fertility Society (1997) The revised American Society of Reproductive Medicine classification of endometriosis. Fertil Steril 67:817-821

15. Jones KD, Haines P, Sultan CJG (2001) Long term follow up of a controlled trial of laser laparoscopy for pelvic pain. J Soc Laparosc Surg 5:111-115

16. Mahmood TA, Templeton A (1990) The impact of treatment on the natural history of endometriosis. Hum Reprod 5:965-970

17. Hornstein MD, Yuzpe AA, Burry KA, Heinrichs L, Buttram VL, Orwoll ES (1995) Prospective randomised double blind trial of 3 versus 6 months of nafarelin therapy for endometriosis associated pelvic pain. Fertil Steril 63:955-962

18. McParland P, Halligan AWF, Taylor DJ, Naftalin NJ (1997) Laparoscopic laser treatment for endometriosis. Gynaecol Obstet Investig 44:38-40

19. Waller KG, Shaw RW (1993) Gonadotrophin releasing hormone analogues for the treatment of endometriosis: long term follow up. Fertil Steril 59:511-515

20. Donnez J, Pirard C, Smets M, Jadoul P, Squifflet J (2004) Surgical Management of Endometriosis. Best Pract Res Clin Obstet Gynaecol 18:329-348

21. Farquhar C, Sutton CJG (1998) The evidence for the management of endometriosis. Curr Opin Obstet Gynaecol 10:321-322
22. Hull ME, Moghissi KS, Magyar DF, Hayes MF (1987) Comparison of different treatment modalities of endometriosis in infertile women. Fertil Steril 47:40-44

23. Hughes E, Brown J, Collins JJ, Farquhar C, Fedorkow DM (2007) Vandekerckhove P. Ovulation suppression for endometriosis, Cochrane Database of Systematic Review

24. European Society of Human Reproduction and Embryology (2007) Guideline for the Diagnosis and Treatment of Endometriosis. ESHRE, Grimbergen

25. Jacobson TZ, Barlow DH, Garry R, Koninckx P (2003) Laparoscopic surgery for pelvic pain associated with endometriosis (Cochrane review). Update Software, Oxford

26. Macoux S, Maheux R, Berube S (1997) The Canadian Collaborative Group on Endometriosis. Laparoscopic surgery in infertile women with minimal or mild endometriosis. N Engl J Med 337:1098-1100

27. Hill NCW, El-Toukhy T, Chandakas S, Grigoriades T, Erian J (2005) Safety of Helica Thermal Coagulator in treatment of early stage endometriosis. J Obstet Gynaecol 25(1):52-54

28. Sutton CJG (1995) Power sources in endoscopic surgery. Curr Opin Obstet Gynaecol 7:248-256

29. Schenken RS, Asch RH, Williams RF, Hodgen GD (1984) Etiology of infertility in monkeys with endometriosis: luteinised unruptured follicles, luteal phase defects, pelvic adhesions and spontaneous abortions. Fertil Steril 41:122-130

30. Koninckx PR, Meuleman C, Demeyere S, Lesaffre E, Cornillie FJ (1991) Suggestive evidence that pelvic endometriosis is a progressive disease, whereas deeply infiltrating endometriosis is associated with pelvic pain. Fertil Steril 55:759-765

31. Murphy AA, Green WR, Bobbie D, de la Cruz ZC, Rock JA (1986) Unsuspected endometriosis documented by scanning electron microscopy in visually normal peritoneum. Fertil Steril 46:552

32. Nisolle M, Casanas-Roux F, Donnez J (2011) Peritoneal Endometriosis: Evaluation of typical and subtle lesions. An atlas of operative laparoscopy and hysteroscopy. Parthenon, New York 